\title{
Solar Driven Geomagnetic Anomalies and Sperm Whale (Physeter macrocephalus) Strandings Around the North Sea: An Analysis of Long Term Datasets
}

\author{
Klaus Heinrich Vanselow ${ }^{*}$, Klaus Ricklefs $^{1}$ and Franciscus Colijn ${ }^{1,2}$ \\ ${ }^{1}$ Forschungs- und Technologiezentrum Westküste der Universität zu Kiel, Hafentörn 1, D-25761 Büsum, Germany \\ ${ }^{2}$ GKSS, Institute for Coastal Research, Max-Planck-Straße 1, D-21502 Geesthacht, Germany
}

\begin{abstract}
To stimulate the discussion about possible reasons for whale strandings, we suggest solar driven geomagnetic variations as one further explanation for this phenomenon. Following this hypothesis that whales may strand due to geomagnetic disturbances we compared annual means of stranding event numbers of sperm whales (Physeter macrocephalus) along the North Sea coasts with yearly averaged numbers of geomagnetic anomaly intensities (aaindices). Based on a Generalised Additive Model technique, our new approach suggests that over the last 400 years $20 \%$ of the stranding events can be correlated with aa-index variabilities. Furthermore, the increased stranding numbers of the last decades could be explained by the exceptional intensive disturbances of the earth's magnetic field in the same period.
\end{abstract}

Keywords: Strandings, sperm whales, sun spot cycle, solar activity, geomagnetic anomalies, temperature anomalies, North Sea.

\section{INTRODUCTION}

Cetacean and especially sperm whale (Physeter macrocephalus) strandings are at anytime spectacular events of great human interest. Around the North Sea they have been comparably well documented for centuries. The high number of reported sperm whale strandings at the end of the last century seems to indicate that the frequency of these events increased. Anthropogenic encroachments such as contaminants or intensive sound disturbances which derange the natural behaviour of the cetacean, have been considered to be a cause (e.g. [1, 2]), while other authors like Smeenk [3] have discussed the fact that an increasing number following the ban of sperm whale hunting in the last century may have resulted in a rising number of strandings. A detailed overview about a large number of possible beaching causes is given e.g. by [1-4]. In order to stimulate the discussion about backgrounds of strandings, we focus on a different possible reason for this phenomenon without diminishing the other legitimate reasons.

Life on earth is influenced significantly by climate. Climate is driven strongly by the energy provided by the sun $[5,6]$. Furthermore, the energy flux from the sun undergoes changing activities and periodicities. Best known are the 27day rotation period of the sun, the 11-year Schwabe sun spot cycle, the 22-year Hale magnetic cycle and the 80-90-year Gleisberg cycle [7]. Over the last decades new findings were published, showing further relations between solar activity, earth climate and possible effects on whale strandings. To introduce the background leading to the assumptions of this

*Address correspondence to this author at the Forschungs- und Technologiezentrum Westküste der Universität zu Kiel, Hafentörn 1, D25761 Büsum, Germany; E-mail: vanselow@ftz-west.uni-kiel.de paper a listing of some correlations between solar activity and climate on earth in terms of possible reasons for whale strandings due to solar activity is given as follows.

Labitzke \& van Loon [8-10] found a strong coupling between atmospheric parameters (e.g. prevalence of easterly or westerly winds in late northern winter) and the 11-year solar cycle. They showed that changes in UV radiation of up to $10 \%$ between solar maximum and minimum within the 11-year solar cycle can influence stratospheric variations in the total ozone concentration as well as in the wind and temperature conditions which can have effects down to the Earths surface climate. Shindell et al. [11] demonstrated this likewise by modelling solar cycle variability (especially the 11-year oscillation), and ozone concentration variations which triggered climatic effects. They concluded that solar cycle variability affects earth surface winds and air pressures and may play a significant role in regional surface temperatures. Friis-Christensen \& Lassen [12] found a close relationship between solar cycle length and earth's surface temperature in the northern hemisphere over the last 130 years. Reid $[13,14]$ described a correlation between the 11year running mean of the sun spot numbers and sea-surface temperature anomalies in all three major ocean basins. Numerical experiments by Weng [15] using a nonlinear approach demonstrate that the 11-year solar activity could be the cause for regional sea surface temperature (SST) variations. Based on modelling results and diatom proxies Jiang et al. [16] suggest a link between solar forcing and natural climate variability. For the last 2000 years their data evaluation for the northern North Atlantic realm shows correlations between the SSTs and irradiance at statistical significant levels. White \& Cayan [17] found periodicities in the global ocean temperature variability with durations comparable to the Hale and Schwabe cycles of the sun. Many of these presented relationships were discussed in a 
review by Tsiropoula [7]. He concluded that the variabilities in sun activities are reflected in the earth climate even though some physical mechanisms are still insufficient known.

In addition to the fact that the sun affects the physical world, physical environmental changes (e.g. day and night, seasonal effects, changes in temperature etc.) in numerous ways can influence biological behaviour and processes on earth. So, a priori, it can not be excluded that, although some aspects of whale strandings are currently not understood and many explanations have been proposed [1, 3, 18, 19], fluctuations in solar activity to a certain extent either directly (e.g. disturbance of the magnetic sense) or indirectly can lead to strandings of cetaceans and especially of sperm whales.

For sperm whales in the North Sea Pierce et al. [4] found a relation of $8.8 \%$ between strandings and positive temperature anomalies. They analysed the same long-term datasets as in this paper using the Generalised Additive Mixed Model. Pierce and co-workers [4] hypothesised that higher temperature anomalies in the waters off southern Norway may result in a shift in prey items of sperm whales into the North Sea and therefore sperm whales may follow those prey items into areas where they are more likely to strand. Especially the preferred prey of sperm whales the boreoatlantic armhook squid (Gonatus fabricii) needs further research about its distribution in the deep water off southern Norway at different environmental conditions. They also stated, that mechanisms linking sperm whale strandings and climate are possible but speculative.

Evans et al. [19] demonstrated correlative associations of cetacean strandings at beaches of Tasmania and southeast Australia from 1920 to 2002 to the weather cycle phenomenon of the zonal westerly winds. They hypothesised that the colder waters produced by these winds resulted in more nutrient rich areas, likely with higher food contents, closer to the shore, which in turn could result in a shift in cetacean distribution into areas where a higher probability of whale strandings every 10 to 13 years occurs [19]. There are indications that these weather phenomena may also be driven by solar activity [20] with a concomitant influence on the atmosphere, resulting in corresponding winds.

In an earlier paper Vanselow \& Ricklefs [21] related the frequency of sperm whale strandings to solar cycle lenghts. Based on a relatively simple statistical approach they showed that over the last three centuries the time series curve for sperm whale strandings around the North Sea [3, 22, personal comm. by Smeenk] and for the smoothed solar cycle length run widely parallel.

According to Georgieva et al. [23] many aspects of solar activity can be detected best by deviations of the geomagnetic field. So in our new analysis, we no longer focus only on the relatively abstract parameter 'smoothed solar cycle length' with its typical periods of roughly 11 years (as applied by [21]). Instead, we investigated the degree of correlation between annual stranding frequency and aa-index. The aa-index is a simple planetary geomagnetic activity index [24], derived from measurements from two approximately antipodal observatories. The easily retraceable time series of measured data goes back to 1868 and for modelled data to 1619 , respectively [24].

\section{DATA AND METHODS}

For the period of the last three centuries all years with observed or predicted minimum sun spot activity (data mainly taken from the internet page ftp://ftp.ngdc.noaa.gov/ STP/SOLAR_DATA/SUNSPOT_NUMBERS/maxmin.new; see also [21]) relating to the roughly 11 year sun spot cycle are listed in Table $\mathbf{1}$.

Table $\mathbf{1}$ also includes the actual length of the solar cycles. To reduce 'noise' in the dataset (a solar cycle is determined by observed sun spots, varying over a wide range from roughly 8 to 17 years) and to take into account that two successive, unequally intensive and at reverse solar polarity 11 years 'Schwabe cycles' are part of one superior 22-years 'Hale cycle' [6], we used smoothed cycle length values. Each solar cycle length (L) was calculated as the 1-2-1weighted average of three subsequent individual periods [21]. The following equation was used (for further explanation see [21]):

$L 121_{n}=\left(L_{n-1}+2 \times L_{n}+L_{n+1}\right) \times 4^{-1}$

Hereby, the smoothed dataset covers the period of the last 27 solar cycles (291 years). The corresponding numbers of sperm whale strandings around the North Sea in the time span of 1712 to 2003 [3, 22, personal comm. by Smeenk] are allocated to these 27 intervals. Solar cycle data from before 1712 are not included, because in the Maunder Minimum (1645 to 1715 ) with only very few sun spots [6] nearly no solar cycles are determinable.

We defined strandings happening in one short period (e.g. a few days) and around one specific location as one "stranding event". The limited number of sperm whale sightings around the North Sea reported by Smeenk and others were not included, because these sightings happened mostly during cycles with many strandings, hence, their consideration would not improve the quality of the performed analyses. To calculate the correlation between number of stranding events per year and the annual geomagnetic deviation given by the aa-index we used the wavelet transformation simulated annual indices from 16192003 given by Nagovitsyn ([24], data available at: http://www.gao.spb.ru/database/ esai/). Sperm whale stranding data again are taken from Smeenk [3, 22, personal comm. by Smeenk].

Compared to our earlier work [21], where results were based on the comparison of 27 parameter pairs of solar cycle lengths and adequate sums of stranding events covering a period of 291 years, now 385 parameter pairs of annual stranding numbers and geomagnetic anomaly indices are analysed. Moreover, the higher temporal resolution of these 385 parameter pairs allows more insight into processes on shorter time scales.

Generalized Additive Models (GAM) [27, 28] were used to investigate possible relations between stranding events and solar cycle lengths and aa-indices, respectively. All analytical runs were performed with the package 'mgcv' [28, 29] in R 2.4.1 (www.r-project.org) using the quasi-poisson distribution for the analysis related to solar cycles and the poisson distribution for the analysis related to aa-indices. In the analysis we used the variance explained by the adjusted coefficient of determination $\mathrm{r}^{2}$. For the sake of completeness, 
the less strict proportion of the null deviance explained by the model was added in parentheses, rather than adapted to the fit parameter.

Table 1. Classification of Sperm Whale Strandings Until 2003 in the Solar Cycles within the Past Three Centuries

\begin{tabular}{|c|c|c|c|c|}
\hline \multirow{3}{*}{$\begin{array}{c}\text { Sun Cycle } \\
\text { Minima } \\
\text { Year }\end{array}$} & \multirow{3}{*}{$\begin{array}{c}\text { Sun Cycle } \\
\text { Length } \\
\text { L }\end{array}$} & \multirow{3}{*}{$\begin{array}{c}\text { Sun Cycle } \\
\text { Smoothed } \\
\text { L121 }\end{array}$} & \multicolumn{2}{|c|}{ Whale Strandings } \\
\hline & & & All & Total \\
\hline & & & Events & Strandings \\
\hline \multicolumn{5}{|l|}{1698.0} \\
\hline 1712.0 & 14.0 & & & \\
\hline 1723.5 & 11.5 & 11.88 & 2 & 2 \\
\hline 1734.0 & 10.5 & 10.88 & 1 & 18 \\
\hline 1745.0 & 11.0 & 10.68 & 1 & 4 \\
\hline 1755.2 & 10.2 & 10.68 & 2 & 5 \\
\hline 1766.5 & 11.3 & 10.45 & 15 & 37 \\
\hline 1775.5 & 9.0 & 9.60 & 4 & 4 \\
\hline 1784.7 & 9.2 & 10.30 & 1 & 1 \\
\hline 1798.3 & 13.6 & 12.20 & 1 & 1 \\
\hline 1810.6 & 12.3 & 12.70 & 0 & 0 \\
\hline 1823.3 & 12.7 & 12.10 & 1 & 1 \\
\hline 1833.9 & 10.6 & 10.90 & 2 & 2 \\
\hline 1843.5 & 9.6 & 10.60 & 0 & 0 \\
\hline 1856.0 & 12.5 & 11.50 & 0 & 0 \\
\hline 1867.2 & 11.2 & 11.69 & 0 & 0 \\
\hline 1878.9 & 11.7 & 11.29 & 0 & 0 \\
\hline 1889.6 & 10.7 & 11.31 & 0 & 0 \\
\hline 1901.7 & 12.1 & 11.71 & 0 & 0 \\
\hline 1913.6 & 11.9 & 11.50 & 0 & 0 \\
\hline 1923.6 & 10.0 & 10.50 & 2 & 2 \\
\hline 1933.8 & 10.2 & 10.20 & 0 & 0 \\
\hline 1944.2 & 10.4 & 10.30 & 5 & 7 \\
\hline 1954.2 & 10.0 & 10.30 & 2 & 6 \\
\hline 1964.9 & 10.7 & 10.80 & 1 & 1 \\
\hline 1976.5 & 11.6 & 11.10 & 5 & 5 \\
\hline 1986.8 & 10.3 & 10.55 & 9 & 10 \\
\hline 1996.8 & 10.0 & 10.10 & 23 & 50 \\
\hline $2006.9^{*}$ & 10.1 & 10.25 & 19 & 40 \\
\hline $2017.7 *$ & 10.8 & & & \\
\hline Sum: & & & 96 & 196 \\
\hline
\end{tabular}

Explanations of definitions are given in Data and Methods. A single animals event contains all strandings at one event. Total strandings represents all reported stranded individuals. *) Data from Schatten [25] and Sello [26].

\section{RESULTS}

Generalised Additive Model Analysis of Strandings and Solar Cycle Lengths

Applying the GAM analysis on L121 smoothed solar cycle lengths and sperm whale stranding data covering the period from 1712 to 2003 (Table 1) results in the smoothed curve in Fig. (1). It suggests that shorter smoothed solar cycle lengths are associated with a higher probability to sperm whale strandings. The approximated significance of the smoothed terms are given by the degrees of freedom d.f. $=2.19$, the result of the F-test $\mathrm{F}=2.592$ and the associated probability value $p=0.052$. The variance explained is the adjusted coefficient of determination $\mathrm{r}^{2}=0.223$ (the proportion of the null deviance explained by the model is $40.4 \%)$.

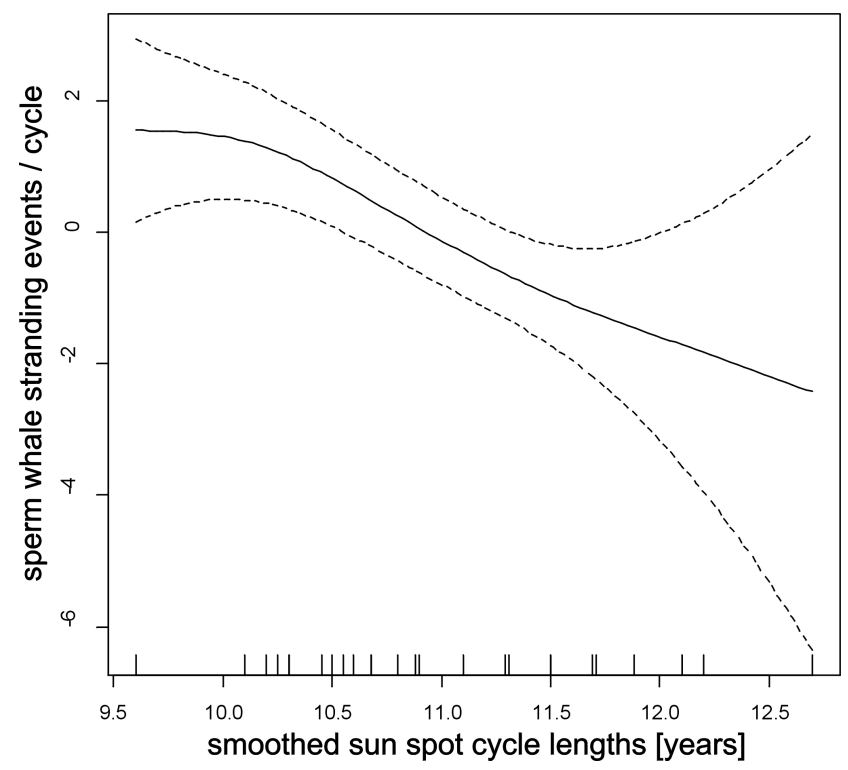

Fig. (1). GAM correlation curve of sun spot cycle lengths and sperm whale stranding events from the adequate cycle intervals from 1712 to 2003. The solar cycle lengths are given as L121 smoothed cycles (see Table 1). The dotted lines represent the $95 \%$ confidence bands. The ticks on top of the $\mathrm{x}$-axis mark the used cycle lengths.

Although the $95 \%$ confidence bands are already fairly close to a longer intercept of the curve a definite widening can be observed at very short and very long cycle lengths. This is due to the very limited number of data points at both ends of the curve.

Running the same analysis only with data of the main migration period of sperm whales (November to March) results in slightly better statistical significant parameters (d.f. $=2.499, \mathrm{~F}=2.501, \mathrm{p}=0.0593$ with a adjusted $\mathrm{r}^{2}=0.245$ (the proportion of the null deviance is $45 \%$ ), data not shown).

\section{Generalised Additive Model Analysis of Strandings and Yearly Geomagnetic Anomalies}

As we would consider smoothed solar cycle length data as a kind of extra-planetary proxy for solar activity and its triggered effects, the short term geomagnetic deviation, in our case represented by the mean annual aa-index [nT], can be understood as the direct response of the earth's magnetic field on changing solar activity (the more solar activity the larger geomagnetic anomalies). Furthermore, the use of aaindex values allows an analysis with a higher temporal resolution in steps of one year compared to the mean solar cycle length data with a period of approximately 11 years. In this way, the analysis can take into account the increasing 
stranding numbers in the second half of the last century in more detail (Table 1). Applying the GAM analysis on 385 parameter pairs of mean annual aa-indices and temporarily corresponding sperm whale stranding data (1619-2003) results in the smoothed curve presented in Fig. (2). It suggests a high probability of whale strandings in years of high geomagnetic deviation. The $95 \%$ confidence bands run close and largely parallel to the curve and also the calculated statistical values d.f. $=1.91$, the result of the $\chi^{2}$-test $\chi^{2}=$ $73.74, \mathrm{p}<0.0001$ with a adjusted $\mathrm{r}^{2}=0.204$ (the proportion of the null deviance explained by the model is $17.5 \%$ ) document the significant correlation between the two parameters.

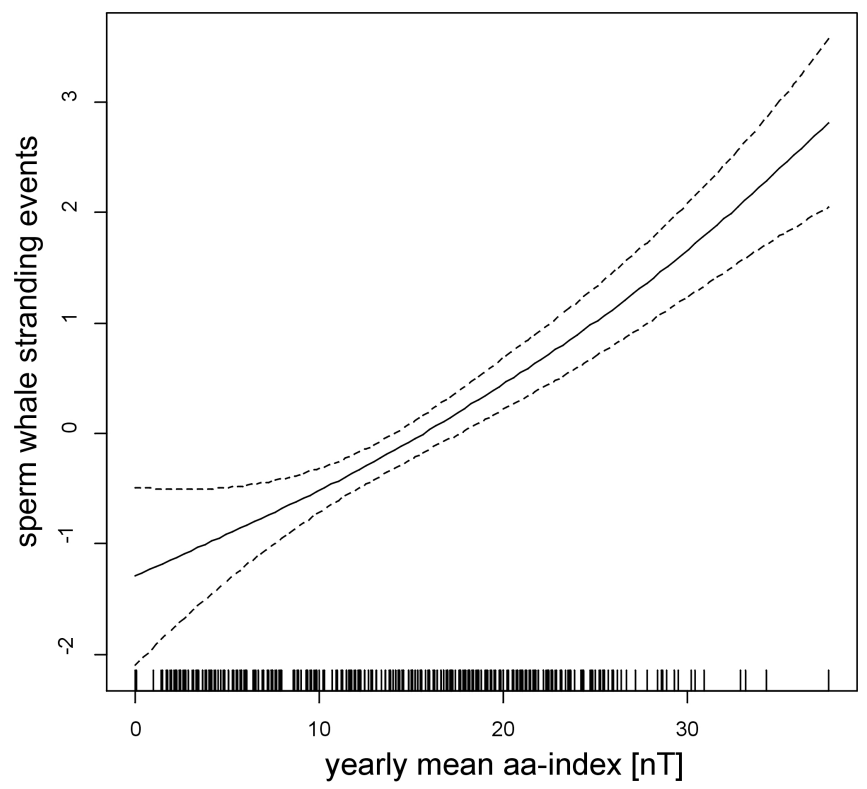

Fig. (2). GAM correlation curve of simulated yearly mean geomagnetic anomalies versus yearly sperm whale stranding events. The dataset covers the period from 1619 to 2003 . The aaindex values are given directly as geomagnetic deviations in $\mathrm{nT}$. The dotted lines represent the $95 \%$ confidence bands. The ticks on top of the $\mathrm{x}$-axis mark the used aa-index values.

Phase shifts of $\pm 1,2$ and 3 years for the correlation between strandings and yearly aa-index data show an adjusted $\mathrm{r}^{2}<0.09$ for all six correlations (data not shown).

\section{DISCUSSION}

All performed statistical analyses show that during phases of higher solar activity, either characterised by shorter sun spot cycle lengths or higher yearly mean aa-index values, more sperm whale strandings have been observed along the North Sea coasts. Using the GAM analysis up to an annual resolution and evaluating the whole curve shape in contrast to the interval analysis used by Vanselow \& Ricklefs [21], 20\% of all sperm whale stranding events around the North Sea can be assigned to the magnitude of the annual mean aa-indices and $22 \%$ on the basis of smoothed solar cycle length data.

Especially in the case of the aa-index it is an interesting aspect that whales may use features of the geomagnetic field for orientation [30, 31]. Klinowska [18] and Walker et al. [32] reported that magnetic contour lines in the oceans often follow continental margins and whales may take advantage of these 'invisible lines' for navigating along their migration routes. The magnitude of these natural geomagnetic field anomalies frequently is of the same order as the disturbances temporarily induced by solar activity [21]. Assuming again that whales actually have a magnetic sense, which is used for orientation along the geomagnetic field lines (possibly by 'seeing' the magnetic field as recently hypothesised for migrating birds by Heyers et al. [33]), temporal deformations of the natural earth's magnetic field anomalies might cause problems for their navigation ability, because the animals are not able to distinguish between both phenomena. So, up to $20 \%$ of the sperm whale strandings around the North Sea could be related to these geomagnetic disturbances quantified by the aa-index values.

This new approach might give a new impulse in the discussion of possible explanations for the significant increase of sperm whale strandings during the past decades (Table 1). In this context it is essential to state that during the last 60 to 70 years the sun's activity has been unusually high compared to the last 1000 years [34] or even 8000 years [35]. Correspondingly, high aa-index values have been observed over this period [36]. According to the relation presented in Fig. (2) or the simple comparison of Fig. (3) the probability of whale strandings should significantly increase in years with high geomagnetic deviances and high aaindices, respectively.

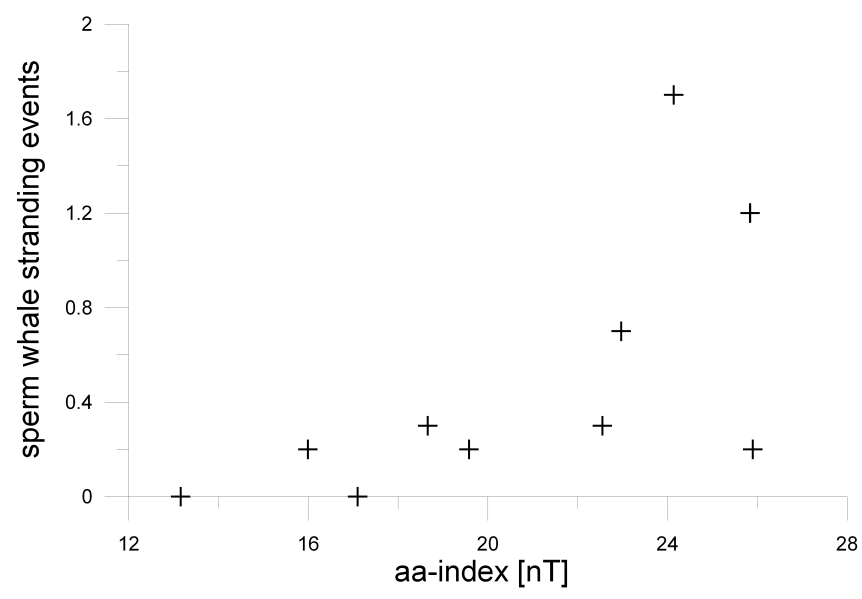

Fig. (3). Comparison of 10 year averaged aa-index values and 10 year averaged whale stranding events for the period from 1901 to 2000 .

The plausibility of this finding gets even more distinct by the fact that other explanations for the high number of sperm whale strandings during the past decades like increasing noise exposure in the oceans due to human activities [37] or a recovery of the sperm whale population after the end of the commercial whaling in the 1980ies [1] were already challenged by Whitehead [38]. Whitehead stated that the sperm whale population size in 1999 was roughly half as big as in 1945, when intensive commercial hunting started. Compared to a pre-whaling value from 1712 the population size in 1999 was even $72 \%$ smaller [38]. This means that around the millennium compared to the past centuries fewer sperm whales were exposed to the risk to end on a North Sea beach. On the other hand it can not be neglected, that there are suggestions that some species of whales, particularly those of the beaked whale family (Ziphiidae), may be particularly sensitive to military sonar activities $[39,40]$. 
However, other associations of cetacean strandings to high levels of noise describe coincidental strandings occurring contemporaneously (but not necessarily nearby) to anthropogenic derived noise.

As outlined, solar driven effects might be directly responsible for some sperm whale strandings around the North Sea by disturbing the whales' magnetic sense. However, Georgieva et al. [23] showed a close parallelism in the temporal evolution of geomagnetic activity (aa-index) and global temperature anomalies (time series from 1856 to 2000). The close correlation of both parameters poses that temperature, or temperature related effects respectively (e.g. [4]) and/or magnetic anomalies exert influence on a part of whale strandings.

Boberg \& Lundstedt [41] suggested a relationship between the electric field strength of the solar wind and the North Atlantic Oscillation (NAO) index. On the other hand, typical meteorological situations influencing sea surface temperature anomalies or even biological processes, like growth rates and distribution patterns of plankton or fish, often can be related to changes of the NAO [42-44]. Zuur \& Pierce [45] found a correlation between catches of squid, a potential prey for sperm whales, in the northern North Sea and the NAO for the time window August to November (data from 1970 to 1999). On a more general basis Learmonth et al. [46] discussed the effect between climatic implemented SST changes, shifts in prey distribution and the spreading of marine mammal species. They reported e.g. that the distribution of some feeding whales can be predicted by means of the surface temperature values and other bathymetric variables due to their effects on prey availability or that some whale species shift their geographic ranges to tracks preferred or required temperature conditions. According to Evans et al. [19], changes in food availability due to cyclic climatic variation can also explain trends in whale strandings. So all this suggests that cetacean strandings are likely to be the result of a complex of many factors, some of which may be more predominant in particular situations, and that it is likely that not one environmental feature is likely to explain all cetacean strandings.

\section{CONCLUSION}

Although the statistical correlation between sperm whale strandings and solar cycle length is pronounced, we agree that it might not be easy to accept the biological relevance of such an abstract parameter like 'smoothed solar cycle length'. However, by the examination of the geomagnetic anomaly (aa-index) a parameter is introduced, which has a relatively high temporal resolution and which physical characteristics can doubtlessly influence animal life (proved e.g. for birds). The relatively close correlation can be considered as a hint for the importance of geomagnetic deviations for whale strandings or also as circumstantial evidence for the general existence of a magnetic sense in whales.

In spite of the fact that our statistical analysis shows a significant correlation of $20 \%$ of all data between a pure physical parameter (geomagnetic field variation) and sperm whale stranding event numbers in the North Sea, we nevertheless concur with many other stranding theories, e.g. with the more biologically substantiated hypothesis that shifts in the distribution and abundance of whales' prey can lead to changes in the whales movement patterns (e.g. [1, 3, $4,19])$. Changes in prey distribution are often due to climatic variation, which can frequently result from astronomical and solar fluctuations. Consequently, it can be difficult to filter out the driving force(s) for whale strandings. However, the next decades may give us the opportunity with the increasing effects of global warming to test whether higher temperature (influenced by man and/or sun) or sun driven geomagnetic anomalies have a consistent effect on the number of strandings. In this context it is noteworthy that the next solar cycles are predicted to be relatively long [47]. This is tantamount to low solar activity compared to the past decades - a phase which was characterised by intensive solar activity and by high numbers of sperm whale strandings around the North Sea.

\section{ACKNOWLEGEMENTS}

We are grateful to S. Adler for statistical assistance and locating literature on the GAM method, and Y. Nagovitsyn for permission of using his aa-index datasets. We thank C. St. Cyr for helpful comments in solar activity, I. Hasselmeier for critical proof-reading, and the reviewers for improving the manuscript by their comments.

\section{REFERENCES}

[1] Goold JC, Whitehead H, Reid RJ. North Atlantic sperm whale, Physeter macrocephalus, strandings on the coastlines of the British Isles and Eastern Canada. Can Field-Nat 2002; 116: 371-88.

[2] Simmonds MP. The meaning of cetacean strandings. Bull Inst R Sci Nat Belg Biol 1997; 67(Suppl.): 29-34.

[3] Smeenk C. Strandings of sperm whales Physeter macrocephalus in the North Sea: history and patterns. Bull Inst R Sci Nat Belg Biol 1997; 67(Suppl): 15-28.

[4] Pierce GJ, Santos MB, Smeenk C, Saveliev A, Zuur AF. Historical trends in the incidence of strandings of sperm whales (Physeter macrocephalus) on North Sea coasts: An association with positive temperature anomalies. Fish Res 2007; 87: 219-28.

[5] Beer J, Mende W, Stellmacher, R. The role of the sun in climate forcing. Quat Sci Rev 2000; 19: 403-15.

[6] Hoyt DV, Schatten KH. The role of the sun in climate change. New York: Oxford University Press 1997.

[7] Tsiropoula G. Signatures of solar activity variability in meteorological parameters. J Atmos Sol-Terr Phy 2003; 65: 46982 .

[8] Labitzke K, van Loon H. Associations between the 11-year solar cycle, the QBO and the atmosphere. Part I: The troposphere and stratosphere in the northern hemisphere winter. J Atmos Sol-Terr Phy 1988; 50: 197-206.

[9] Labitzke K, van Loon H. Associations between the 11-year solar cycle and the atmosphere. Part V: Summer. J Climate 1992; 5: 24051.

[10] Labitzke K, van Loon H. Total ozone and the 11-year sunspot cycle. J Atmos Sol-Terr Phy 1997; 59: 9-19.

[11] Shindell D, Rind D, Balachandran N, Lean J, Lonergan P. Solar cycle variability, ozone, and climate. Science 1999; 284: 305-8.

[12] Friis-Christensen E, Lassen K. Length of the solar cycle: An indicator of solar activity closely associated with climate. Science 1991; 254: 698-700.

[13] Reid GC. Solar total irradiance variation and the global sea surface temperature record. J Geophys Res 1991; 96: 2835-44.

[14] Reid GC. Solar variability and its implications for the human environment. J Atmos Sol-Terr Phy 1999; 61: 3-14.

[15] Weng H. The influence of the $11 \mathrm{yr}$ solar cycle on the interannualcentennial climate variability. J Atmos Sol-Terr Phy 2005; 67: 793805 .

[16] Jiang H, Eiriksson J, Schulz M, Knudsen K-L, Seidenkrantz M-S. Evidence for solar forcing of sea-surface temperature on the North Icelandic Shelf during the late Holocene. Geology 2005; 33: 73-6. 
[17] White WB, Cayan DR. Quasi-periodicity and global symmetries in interdecadal upper ocean temperature variability. J Geophys Res 1998; 103: 21335-54.

[18] Klinowska M. Cetacean "Navigation" and the geomagnetic field. J Navigation 1988; 41: 52-71.

[19] Evans K, Thresher R, Warneke RM, et al. Periodic variability in cetacean strandings: links to large-scale climate events. Biol Lett 2005; $1: 147-50$.

[20] Thresher RE. Solar correlates of Southern Hemisphere mid-latitude climate variability. Int J Climatol 2002; 22: 901-15.

[21] Vanselow KH, Ricklefs K. Are solar activity and sperm whale Physeter macrocephalus strandings around the North Sea related? J Sea Res 2005; 53: 319-27.

[22] Smeenk C. A historical review. In: Tougaard S, Kinze C, Eds. Proceedings from the Workshop: Sperm Whale Strandings in the North Sea. Fisheries and Maritime Museum, Esbjerg: Biological Papers 1999; 1: 6-9.

[23] Georgieva K, Bianchi C, Kirov B. Once again about global warming and solar activity. Mem S A It 2005; 76: 969-72.

[24] Nagovitsyn Y. Solar and geomagnetic activity on a long time scale: reconstructions and possibilities for predictions. Astron Lett 2006; 32: $344-52$.

[25] Schatten KH. Solar activity and the solar cycle. Adv Space Res 2003; 32: 451-60.

[26] Sello S. Solar cycle activity: A preliminary prediction for the cycle \#24. Astron Astrophys 2003; 410: 691-3.

[27] Hastie TJ, Tibshirani RJ. Generalized additive models. Vol. 43 of Monographs on Statistics and Applied Probability. London, UK: Chapman and Hall 1990.

[28] Wood SN. Generalized additive models: an introduction with R. London, UK: Chapman and Hall 2006.

[29] Venables WN, Ripley BD. Modern applied statistics with S, New York: USA, Springer 2002; p. 495.

[30] Kirschvink JL. Magnetoreception: Homing in on vertebrates. Nature 1997; 390: 339-40.

[31] Walker MM, Dennis TE, Kirschvink JL. The magnetic sense and its use in long-distance navigation by animals. Curr Opin Neurobiol 2002; 12: 735-44.

[32] Walker MM, Kirschvink JL, Ahmed G, Dizon AE. Evidence that fin whales respond to the geomagnetic field during migration. J Exp Biol 1992; 171: 67-78.

[33] Heyers D, Manns M, Luksch H, Güntürkün O, Mouritsen H. A visual pathway links brain structures active during magnetic compass orientation in migratory birds. PLoS ONE 2007; 2-e937: $1-6$.
[34] Usoskin IG, Solanki SK, Schüssler M, Mursula K, Alanko K. Millennium-scale sunspot number reconstruction: Evidence for an unusually active sun since the 1940s. Phys Rev Lett 2003; 91: 211101-1-4.

[35] Solanki SK, Usoskin IG, Kromer B, Schüssler M, Beer J. Unusual activity of the Sun during recent decades compared to the previous 11,000 years. Nature 2004; 431: 1084-7.

[36] Clilverd MA, Clarke E, Ulich T, Linthe J, Rishbeth $\mathrm{H}$. Reconstructing the long-term $a a$ index. J Geophys Res 2005; 110: A07205.

[37] Sonntag RP, Lütkebohle T. Potential causes of increasing sperm whale strandings in the North Sea. Deutsche Hydrogra Z 1998; 8(Suppl): 119-24.

[38] Whitehead H. Estimates of the current global populationsize and historical trajectory for sperm whales. Mar Ecol Prog Ser 2002; 242: 295-304.

[39] Frantzis A. Does acoustic testing strand whales? Nature 1998; 392: 29.

[40] Simmonds MP, Lopez-Jurado LF. Whales and the military. Nature 1991; 351: 448.

[41] Boberg F, Lundstedt $\mathrm{H}$. Solar wind variation related to fluctuations of the North Atlantic Oscillation. Geophys Res Lett 2002; 29: 1-4.

[42] Guisande C, Cabanas JM, Vergara AR, Riveiro I. Effect of climate on recruitment success of Atlantic Iberian sardine Sardina pilchardus. Mar Ecol Prog Ser 2001; 223: 243-50.

[43] Barton AD, Greene $\mathrm{CH}$, Monger BC, Pershing AJ. Continuous plankton recorder survey phytoplankton measurements and the North Atlantic Oscillation: interannual to multidecadal variability in the Northwest Shelf, Northeast Shelf, and Central North Atlantic Ocean. Prog Oceanogr 2003; 58: 337-58.

[44] Drinkwater K, Belgrano A, Borja A, et al. The response of marine ecosystems to climate variability associated with the North Atlantic Oscillation. In: Hurrell J, Kushnir Y, Ottersen G, Visbeck M, Eds. The North Atlantic Oscillation: climatic significance and environmental impact. American Geophysical Union. Washington DC: Geophysical Monograph Series 2003; Vol. 134: pp. 211-34.

[45] Zuur AF, Pierce GJ. Common trends in northeast Atlantic squid time series. J Sea Res 2004; 52: 57-72.

[46] Learmonth JA, MacLeod CD, Santos MB, Pierce GJ, Crick HQP, Robinson RA. Potential effects of climate change on marine mammals. Oceanogr Mar Biol 2006; 44: 431-64.

[47] Komitov BP, Kaftan VI. Solar activity variations for the last millennia. Will the next long-period solar minimum be formed? Geomagn Aeronomy 2003; 43: 553-61.

(C) Vanselow et al.; Licensee Bentham Open.

This is an open access article licensed under the terms of the Creative Commons Attribution Non-Commercial License (http://creativecommons.org/licenses/by$\mathrm{nc} / 3.0 /$ ) which permits unrestricted, non-commercial use, distribution and reproduction in any medium, provided the work is properly cited. 